\title{
A NEW AND IMPROVED \\ BELT FOR AN ARTIFICIAL BLADDER OPENING
}

Roy H. NyQuist, M.D.

Spinal Cord Injury Service, Veterans Administration Hospital, Long Beach, California, and the Department of Physical Medicine and Rehabilitation, Medical School, University of California, Los Angeles, California

THIS communication describes a new belt for fixation of a urine-collecting bag used for an ileal loop ('Bricker') bladder.

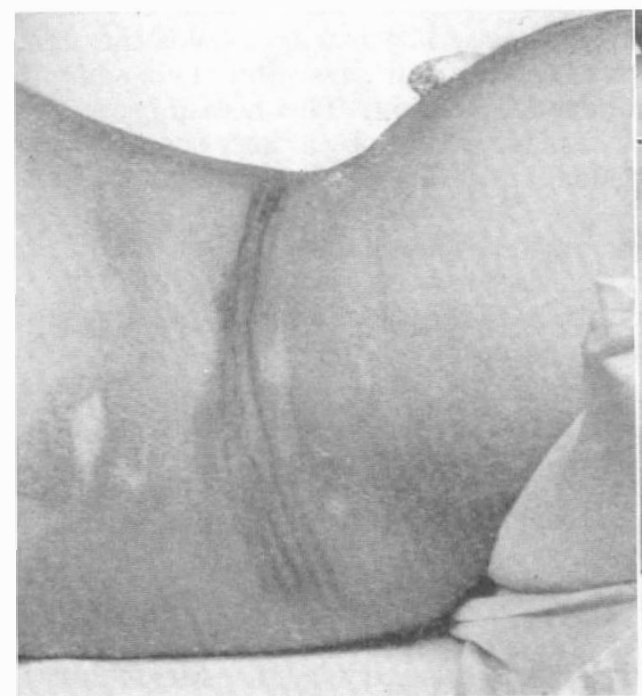

FIG. I.

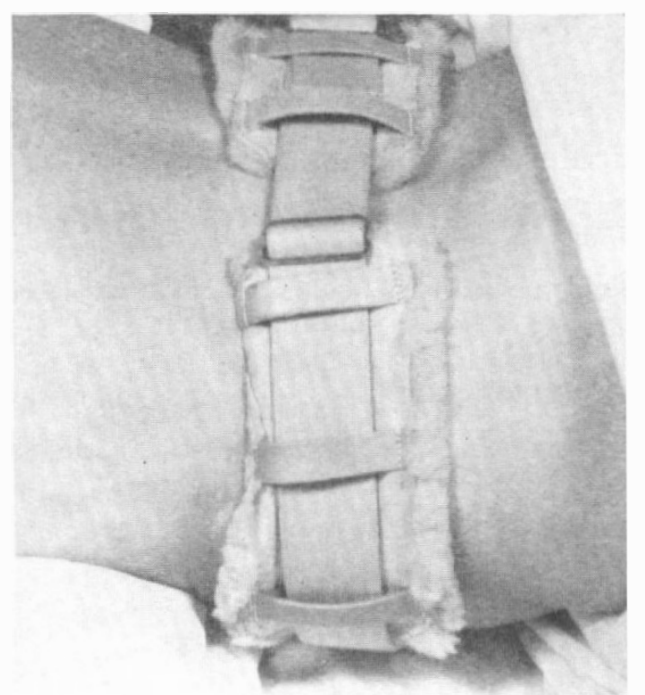

FIG. 3.

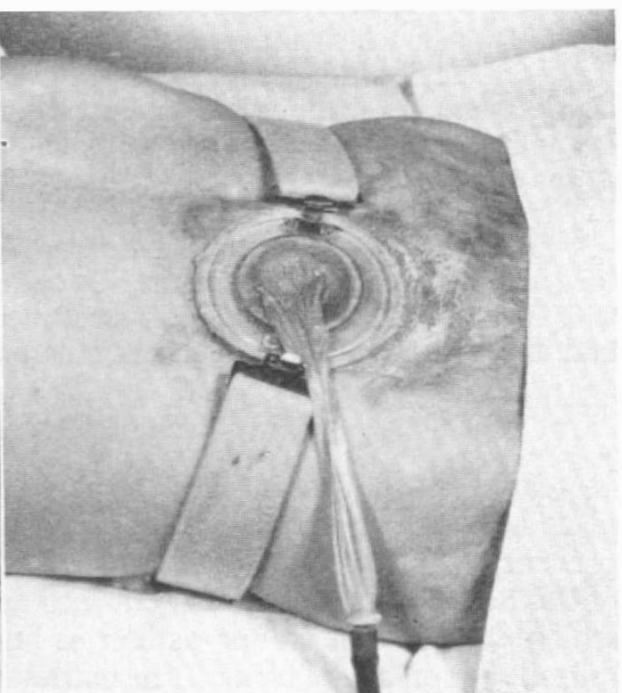

FIG. 2.

Fig. I

Shows healed scars of long narrow decubitus ulcer previously caused by narrow urine-soaked belt for artificial ileal loop bladder. Scar is along the area just above the left iliac crest.

\section{FIG. 2}

Shows appearance of urine-collecting ileostomy ring device and manner of attachment of belt to the device by means of stainless steel pieces with properly sized slots.

Fig. 3

Shows how belt is adjusted at both ends by means of stainless-steel slotted 'keepers' and how the sheepskin pads are made with belt leather loops and how they are positioned on the belt along the flanks above the iliac crests. 
The patient, 40 years of age, was injured by five bullets in 1957, sustaining a complete paraplegia below T4. Two years later a cutaneous uretero-ileostomy ('Bricker') was performed elsewhere. He was first seen at our hospital in November 1964. In addition to multiple decubitus ulcers at sacrum, ischium and trochanter, he had a long narrow pressure ulcer for the $\frac{3}{4}$-inch belt which, in spite of maximum tightening, did not keep the collecting device securely anchored, so that urine soaked his clothes by day and his bed at night. The constant urinary odour made him avoid people, he lived withdrawn, almost like a hermit, and was depressed to the degree of toying with suicidal ideas.

Figure I shows the healed scars of the pressure sore that had been caused by the urine-soaked narrow belt. The new belt (figs. 2 and 3 ) consists of elastic webbing material, I $\frac{1}{2}$ inches wide, fitted with a sheepskin pad, 3 inches wide, with leather belting loops through which the wide elastic webbing passes. The new belt holds the urinecollecting device in place for as long a period of time as four days without changing the skin cement and without leakage because of adequate tension. This new improved belt is not available on the open market and must be made to order by a brace shop. As soon as the elastic webbing looses its elasticity, it should be replaced. Two belts are provided for hygienic reasons.

In Figure 2 is shown the metal part which is made from stainless steel with a $1 \frac{1}{2}$ inches long slot for the attachment to the belt and a smaller slot for attachment to the ring.

Figure 3 shows the stainless-steel metal pieces ('keepers'), for adjustment of each end of the elastic webbing belt over the back.

\section{COMMENT}

An artificial bladder requires an efficient urine-collecting device to be held in place securely by an adequate belt. Such a belt must provide enough tension to prevent the ileostomy ring device from slipping by body movement. The width of the belt is important lest it cut into an anesthetic area causing a decubitus ulcer which was the case in our patient as long as he wore the narrow belt which permitted the spillage of urine. The extra width and decreased local pressure, achieved by means of the sheepskin pads, has allowed the scarred area to remain healed.

A similar type belt may be useful also for a colostomy or for other urinecollecting devices.

\section{SUMMARY}

A new and improved belt for an artificial bladder opening has been described.

\section{RÉSUMÉ}

Une ceinture nouvelle et perfectionnée pour une artificielle ouverture de la vessie est décrite.

\section{ZUSAMMENFASSUNG}

Ein neuer und verbesserter Gürtel für eine künstliche Blasenöffnung wird beschrieben. 